nishing the excitability of the nerves, break or weaken the chief link in this chain of morbid changes, and thus permit the ordinary powers of the system to operate with less embarrassment.

Supposing this view to be correct, experience alone can teach what narcotics, and what mode of applying them, are best adapted to the purpose.

The benefit afforded by opium is undeniable; yet that does not exclude the possibility of the ointment of veratria being of much greater effect, and the application of it to the region of the sacrum appears to afford the readiest channel by which the pelvic nerves can be acted on.

My recommendation, however, of this remedy is not founded on speculation, but on experience; and $I$ have a just confidence that success will also attend the employment of it in your practice, if you will consent to make the trial.

May I then request you to take the trouble to mark the result of your experience on the inclosed table, and transmit it to me. Your doing so will confer on me a great obligation, and contribute, as I anticipate, to the diffusion of a more exact knowledge, among the profession at large, of the nature and treatment of this painful and distressing malady. I have the honour to be, your most obedient servant,

J. Stevenson Bushnan. Castle Cary, Somerset, Oct. 1, 1840.

Table to be filled up and returned to Dr. Bushnan.

1. Number of case.

2. The age of patient.

3. Whether single, married, or widow.

4. If had any family.

5. Duration of dysmenorrhœa.

6. Whether discharge is simple or membranous.

7. Is there any suspicion of inflammation?

8. How long before the discharge does pain begin?

9. Does the pain cease on the appearance of the discharge?

10. Does the pain accompany the discharge?

11. Does pain appear only towards the end of the period?

12. Is the discharge copious?

13. Are there violent efforts at the monthly periods, without discharge?

usual susceptibility of sentient nerves pro duce similar derangements.

3. That the nerves of the uterus are unusually susceptible of irritation at the men. strual periods.

4. That derangements of nervons action disturb secretion, even though secretion be not directly dependent on the nerves, being a function of the vascnlar system only.
14. Does the discharge flow, drop by drop, with pain?

15. Can you trace distinct abortion to dys menorrboea?

16. Is leucorrhoea present, and to what extent?

17. Treatment by ointment of veratria.

15. Result.

N.B.-Anv remarks can be written below. To be sioned with the name and address of the communicant.

\section{REPLY FROM ST. GEORGE'S IN} THE EAST.

\section{To the Editor of THE LANCET.}

Sir:-I trust to your impartiality for the insertion of a reply to the anonymous com. munication inserted in your Journal of last week, from a person who has styled himself “A Medical Practitioner of St. George's IN THE EAST." I have nothing to retract or disavow as regards the sentence in my letter which has apparently excited the impotent wrath of your learned correspondent; with the exception that he has omitted the little adverb "nearly," which might, perhaps, in some measure, have modified the obnoxions sentence, and rendered it somewhat rore palatable to him. He ought, however, to have remembered that the letter alluded to was hastily written, to an ignorant woman, and was not intended for publication, or to be read by such an enlightened critic as he appears to be. The letter was produced by the woman at the inquest, and I could possibly have no control over its publication in the newspapers. With regard to the other observations of your correspondent, I dare say he is already aware that I have for a long time past discontinued labif-guinea midwifery (which, by-the-by, is the standard fee in the neighbourhood among the com. mon people, aud for which sum many re. spectable practitioners still continue to attend), and, doublless, some of my relinquished obstetrical patients have fallen to his share, which circumstance will suffciently explain his apparent acquaiutance with the matter. I think the documents I have inclosed will prove to you that the in. stitution mentioned by your correspondent, is not a "mere nomiual one," nor yet such a "perfect nouentity" as he appears to be.

I shrew dly suspect your correspondent to be one of those numerous practitioners who infest this populous locality without legal qualification; but you, Mr. Editor, mast know from experience, that curs will bark and howl, although they seldom bite or do much mischief. I am, Sir, your obedient servant,

Cannon-street-road, Sept. 21, 1840. 
* * Our correspondent of last week will find nothing to reply to in the abov e letter, under an anonymous signature. For our own part we should hold such institutions as East, West, North, and South London "Lying-in Institutions" in the most sovereign contempt, did we not find reason too often to regard them as dangerous and hypocritical both to patients and the public; and we never see the name of a physician professing claims to respectability and reputation-such as Dr. Francis H. Ramsbotham may think himself entitled to put forth-attached to the circulars and advertisements of these adventurous establishments, without a feeling of regret on behalf of the good name and welfare of the profession.

While on this subject, we may take the opportunity of observing that very often, in these circulars, the most unwarrantable liberties appear to be taken with the names of professional men, to promote the object of the advertisers. We subjoin an example extracted, verbatim, from a hand-bill recently received from a correspondent in Southwark,-a melancholy specimen of the point of degradation to which the name of public "Medical Charity" is reduced, in its conversion to the purposes of private gain :-

\section{"AT THE REVOLVING LIGHT,}

"4, PARK-STREET, BOROUGH-MARKET, "Mr. WAY,

"Surgeon, Accoucheur, Cupper, Dentist, and Herbalist (late Cupper in an extensive Hospital),

"May be consulted at any time of the day relative to all diseases incidental to the human frame. The experience which Mr. Way has had in the hospitals of this and other countries, as well as in his private practice, enables him to assert (without fear of contradiction) his claim to distinction in every branch of his profession.

"Mr. Way has been peculiarly successful in relieving and curing the following disorders, viz., rheumatism, pains in the head, limbs, stomach, and bowels, lumbago (or weakness in the loins), tatulence, \&c. \&c., which he cures in a few days; as also the complaints to which females and children are peculiarly subject; and he is surprisingly fortunate in curing that destructive disease (which cannot here be named), under the influence of which, thousands of both sexes sink from want of proper care and early application to some competent and experienced surgeon.

"If Mr. Way be called to attend the wives of poor persons in their accouchements, his charge is one-half of the usnal fee; and he extracts the teeth of the poor, with his newly-invented and highly-approved instruments, every morning until ten o'clock, upon the same terms; and he vaccinates gratis, on Mondays, Wednesdays, and Fridays.

“*** Dr. Blandell's institution for deli* vering poor pregnant women is placed under the immediate superintendence of $\mathrm{Mr}$ : Way, who delivers letters to those who are within its limits ; securing to them the attendance of competent medical men, free of expense. Dr. Blundell or Mr. Way will attend in all urgent cases, and no person so attended will be dismissed until her state is approved of by Dr. Blundell."

\section{SUGGESTIONS OF AN ATTORNEY} TO A SURGEON.

\section{To the Editor of THE LANCET.}

SIR:-Amid all the advances that the medical profession is making in this reforming age, and to none is it so largely indebted as to yourself, one barbarous and most injurious custom still clings to the general practitioner, and, until it be abolished, must continue to debase him in the estimation of the public, and render that which ought to be purely a scientific profession, a compound of trading and chicanery; I allude to the disgraceful practice of seeking remuneration for medical time and skill through the supply of inordinate quantities of medicine! I do think, Sir, that in the present enlightened age, and for the honour and credit of the profession, this obnoxious system should be at once exploded by a consentaneons agreement of its members, aud thus get rid of the opprobrium of sending physic, less for the benefit of the patient than that of the practitioner. The public now suppose that a medical man's time and advice are of no value, as he sets none upon them himself in his accounts, and they are, therefore, indifferent as to the trouble they give him in visits, for which they do not pay, while they are very ready to grumble at his charge for medicine; not considering that, in towns, it is under the existing system, the only and very inadequate means of remuneration for his time and skill, as well as for the remedy. This is a very proper subject to be taken up by the medical associations, for if the profes. sion could be induced to co-operate thereon, and aqree upon making regular charges for their time and advice, and more moderate ones or none at all for medicine, they would both greatly add to their respectability, and diminish their expenses in the articles of drugs and phials.

I make these remarks, partly, from a pa- 